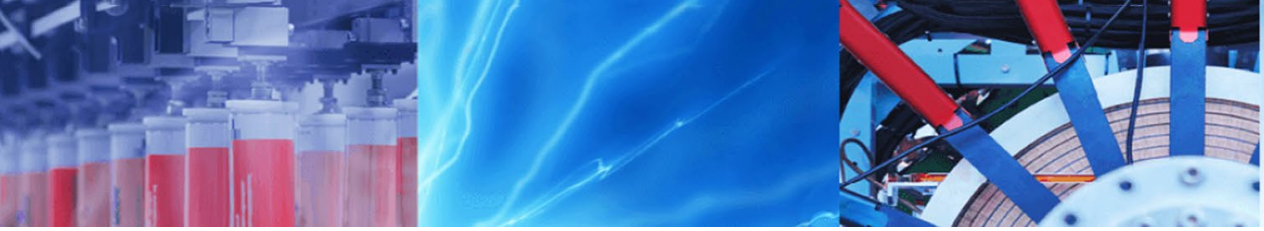

Research Article

\title{
Colloidal interaction between vinylacetate ethylene latex stabilized by polyvinyl alcohol and portland cement
}

\author{
Yu Jin ${ }^{1}$ (i) $\cdot$ Dietmar Stephan $^{1}$ \\ (c) Springer Nature Switzerland AG 2018
}

\begin{abstract}
Interaction between three Vinylacetate Ethylene (VAE) latices with varied surface properties (charge or PVOH stabilized) and cement were studied, through the combined techniques of adsorption and zeta potential measurement. The results showed that all the VAE latices possessed a negative charge in neutral $\mathrm{pH}$, but a lower charge density at a high $\mathrm{pH}$. The non-adsorbed amount was excluded, based on extrapolation from the linear regression of the total depletion amount. Thereof, the calculated results indicated an analogous Langmuir type adsorption for all the latices. The zeta potential results showed a negligible effect of the non-ionic latices on the electro kinetic properties of the cement. This revealed the significance of PVOH on the adsorption of non-ionic latices.
\end{abstract}

Keywords Non-ionic latex · Polyvinyl alcohol · Adsorption · Cement

\section{Introduction}

Synthetic polymer has been used to modify cement based materials for many years [1, 2], of which latex or polymer dispersions being one of the most important categories. Latex modified cement or concrete improves the elastic modulus, adhesion, impact resistance, abrasion resistance, etc. of the hardened material [3]. The synergy effect of the latex modified cement composite is related to its microstructure [4]. As a result of its positive effects, studies on the microstructure of latex modified cementitious materials have drawn great attention lately [5-8].

Recently researchers have gradually come to focus on the interaction mechanism between latex and cement in colloid systems [9-12]. Interaction in a colloid system is important with respect to cement hydration, as well as to the distribution of the polymer film afterwards, since it determines the microstructure of the composite. Merlin et al. [9] have investigated the interaction between non-ionic methyl methacrylate/butyl acrylate latex and pure cement minerals by means of a depletion method. Although negligible adsorption was found for the non-ionic alkyl phenol poly(ethylene oxide) surfactant, the adsorption of latex particles was remarkable; this being attributed to the negative surface charge of the latex polymer. Plank et al. [10] have studied the adsorption of anionic and cationic latices on cement by means of electroacoustic measurements, with preferred adsorption due to opposite surface charges being postulated. Lu et al. [12] have found that the adsorption of polystyrene latices on cement is dependent on the surface charge density of the latex particles, which significantly affects the rheology of the mixture.

Vinylacetate Ethylene (VAE) latex stabilized by partially hydrolyzed poly (vinyl alcohol-co-vinyl acetate) $(\mathrm{PVOH})$ is considered to be non-ionic. Interaction between latex particles and cement, besides electrostatic forces, may indicate weak adsorption, which should actually be similar to the low adsorption amount of $\mathrm{PVOH}$ on minerals, either in the presence of polyacrylic acid [13] or sodium oleate [14]. In other words, electrostatic interaction is the main driving force for the adsorption of polymers on minerals. Kaufmann et al. [11] have investigated the interaction between VAE latex and

Dietmar Stephan, stephan@tu-berlin.de | 'Technische Universität Berlin, Gustav-Meyer-Allee 25, 13355 Berlin, Germany.

SN Applied Sciences (2019) 1:129 | https://doi.org/10.1007/s42452-018-0138-0 
cement by means of the electroacoustic method, speculating that limited adsorption occurs, since little influence on the zeta potential of the cement suspension was observed.

However, VAE based dispersible polymer powder, which is chemically similar to VAE latex stabilized by PVOH, has been observed to affect the hydration of tricalcium aluminate $\left(C_{3} A\right)$, behaving differently when interacting with tricalcium silicate $\left(C_{3} S\right)[15,16]$. Furthermore, changes in the rheology of VAE modified cement paste indicates moderate adsorption [17]. Accordingly, in this study two model VAE latices, stabilized by PVOH and one reference anionic VAE latex possessing an anionic surfactant, were investigated to clarify the possibility of existing interaction mechanisms, other than electrostatic forces between PVOH stabilized latex and cement. The first part of the study was focused on surface characterization of the VAE latices. Consequently, adsorption or depletion was semiquantitatively determined by a method revised according to Merlin et al. [9]. The zeta potential of cement-latex suspensions was also determined, in order to indicate the possible influence of latex adsorption on electrokinetic properties and to provide indirect proof of an adsorption mechanism. Moreover, the adsorption of $\mathrm{PVOH}$ on clinker phases was measured, in order to link the behavior of individual PVOH with VAE latex, stabilized by PVOH.

\section{Materials and methods}

\subsection{Materials}

Two model VAE latices stabilized by PVOH (nominated as latex $A$ and $B$ ) and one VAE latex stabilized with anionic surfactant (2-Acrylamido-2-methylpropane sulfonic acid, nominated as latex C), together with a 20 wt $\%$ PVOH solution (weight average molecular weight $\sim 27,000 \mathrm{Da}$, hydrodynamic radius $\sim 5 \mathrm{~nm}$ ) were provided by Wacker Chemie, Burghausen/Germany. PVOH is freely dispersed, adsorbed or grafted on the surface of VAE particles to impart steric repulsion among particles [18]. PVOH corona appears on the surface of latex particles, as illustrated in the literature [19] (Fig. 1).

Ordinary Portland cement, CEM I 42.5 R provided by Schwenk Zement, Bernburg/Germany, with a mineral composition of tricalcium silicate (59.9 wt\%), dicalcium silicate $(9.4 \mathrm{wt} \%)$, tricalcium aluminate $(7.9 \mathrm{wt} \%)$, tetracalcium aluminate ferrite ( $9.2 \mathrm{wt} \%)$, anhydrite (3.6 wt\%), calcite (3.4 wt\%) etc., was used in this study. Pure tricalcium silicate and tricalcium aluminate synthetic mineral were purchased and provided by Wacker Chemie and checked with XRD prior to this study.

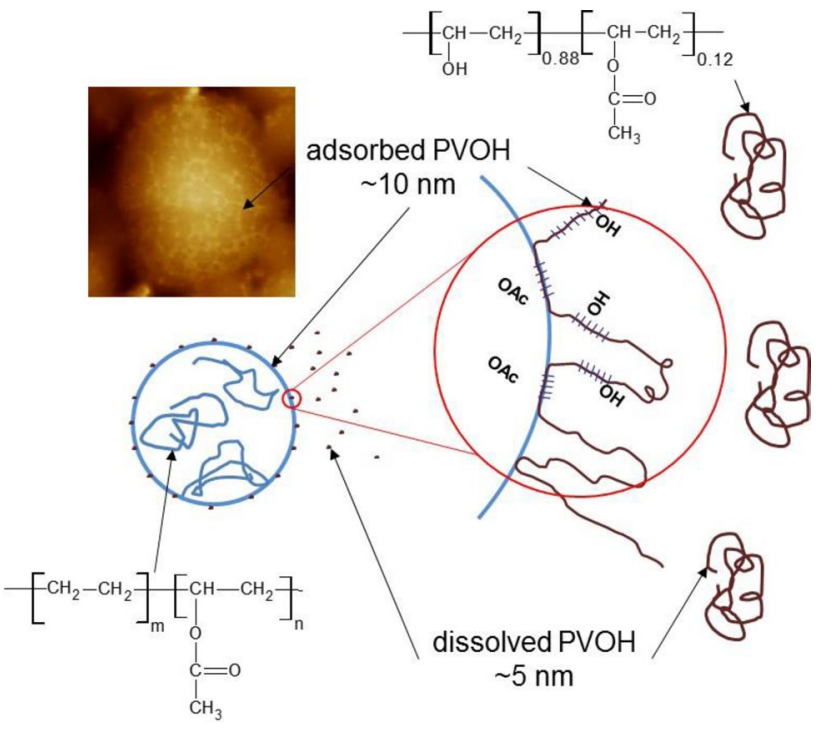

Fig. 1 Schematic illustration of VAE latex stabilized by PVOH (based on literature $[18,19]$, AFM image from an unpublished work)

All materials were used without further purification. Deionized water (conductivity $\sim 0.055 \mu \mathrm{S} / \mathrm{cm}$ ) was used for all experiments.

\subsection{Characterization of the latex polymer and minerals}

The composition and characteristic properties of the latices have been presented in Table 1. The characterization methods used here, have been described elsewhere [20]. According to the results, non-ionic latex $A$ and $B$ had differences in chemical composition and separable $\mathrm{PVOH}$ content. The particle charge density of the latices was determined by titration of $15 \mathrm{~mL} 0.2 \mathrm{wt} \%$ polymer dispersions with $0.01 \mathrm{~mol} / \mathrm{L}$ cationic PDADMAC (polydiallyldimethylammonium chloride), either in deionized water or in an alkaline solution $(\mathrm{NaOH}, \mathrm{pH}=12.5)$. This corresponds to a charge amount of $0.01 \mathrm{eq} / \mathrm{L}$. The amount of charge can be calculated using the volumetric consumption of the PDADMAC solution, which is needed to reach the Isoelectric Point (IEP) of the streaming potential.

The specific surface area of the minerals was determined by the Blaine test, the BET method and with laser granulometry. The Blaine test was carried out with an Elektronisches Blaine-Gerät from Testing Bluhm and Feuerherdt $\mathrm{GmbH}$, Berlin/Germany. The BET method was undertaken with a Sorptomatic $1990^{\circledR}$ from CE Instruments, Austin, Texas/USA. All minerals were ultrasonically dispersed in 2-propanol prior to laser granulometry and measurement with a Mastersizer $2000 \mathrm{~S}$ from Malvern, Worcestershire/UK. The specific surface areas of the minerals were calculated based on the general model of particle 
Table 1 Characterization of VAE Latices

\begin{tabular}{lllllrr}
\hline Latex & Solid (wt\%) & $\mathrm{PVOH}^{\mathrm{a}}(\mathrm{wt} \%)$ & $\begin{array}{l}\text { Specific surface } \\
\text { area }\left(\mathrm{m}^{2} / \mathrm{g}\right)\end{array}$ & $\begin{array}{l}\text { Number mean } \\
\text { particle size }(\mu \mathrm{m})\end{array}$ & $\mathrm{MFFT}\left({ }^{\circ} \mathrm{C}\right)$ & $\mathrm{T}_{\mathrm{g}}\left({ }^{\circ} \mathrm{C}\right)$ \\
\hline $\mathrm{A}$ & $55.5 \%$ & $4.3 \%$ & 7.14 & 0.43 & $<0$ & 0 \\
$\mathrm{~B}$ & $57.7 \%$ & $5.5 \%$ & 7.13 & 0.43 & 6 & 22 \\
$\mathrm{C}$ & $53.2 \%$ & - & 14.8 & 0.28 & $<0$ & 10 \\
\hline
\end{tabular}

A/B/C: vinyl acetate-ethylene copolymer

${ }^{a}$ Amount in supernatant after ultracentrifuging at $40,000 \mathrm{rpm}$ for $2 \mathrm{~h}$
Table 2 Specific surface area of minerals

\begin{tabular}{llll}
\hline Mineral & BET $\left(\mathrm{m}^{2} / \mathrm{g}\right)$ & Blaine $\left(\mathrm{m}^{2} / \mathrm{g}\right)$ & $\begin{array}{l}\text { Laser granu- } \\
\text { lometry } \\
\left(\mathrm{m}^{2} / \mathrm{g}\right)\end{array}$ \\
\hline Cement & 1.01 & 0.40 & 0.22 \\
$\mathrm{C}_{3} \mathrm{~S}$ & 0.77 & 0.35 & 0.39 \\
$\mathrm{C}_{3} \mathrm{~A}$ (cubic) & 0.91 & - & 0.37
\end{tabular}

size distribution and irregular particle shape. All specific surface area results have been summarized in Table 2.

\subsection{Adsorption measurements}

Latex adsorption on cement, $\mathrm{C}_{3} \mathrm{~S}$ and $\mathrm{C}_{3} \mathrm{~A}$ was investigated. $18 \mathrm{~g}$ polymer dispersions with different concentrations, ranging from 0 to $5 \mathrm{wt} \%$, were prepared. Half of the polymer dispersion was mixed with $1 \mathrm{~g}$ of mineral for 1 min with a vortex mixer from VWR. Subsequently, a three step method, put forward by Merlin et al. [9], was carried out to separate the fine mineral particles from the polymer dispersions. Firstly, the tube of polymer/mineral mixture was kept upright for $10 \mathrm{~min}$; secondly, the supernatant was extracted and allowed stand for a further $20 \mathrm{~min}$ for nonionic latex, or centrifuged at $100 \mathrm{~g}$ force for the anionic latex, respectively. The second supernatant was recovered with the addition of $0.5 \mathrm{~mL}$ of $30 \mathrm{wt} \% \mathrm{HCl}$. Finally, the second supernatant was diluted to the same volume as the other untreated half polymer dispersions. Turbidity was measured with a Shimadzu UV 1650 PC spectrometer, at a single wavelength of $800 \mathrm{~nm}$ (non-ionic latex) or $850 \mathrm{~nm}$ (anionic latex). Depletion was calculated directly, based on the ratio between the values of the supernatant and the untreated polymer dispersions.

$\mathrm{PVOH}$ adsorption was investigated on clinker phases. $2.7 \mathrm{~g}$ of polymer solution, with different concentrations ranging from 0 to $0.20 \mathrm{wt} \%$, were prepared. The solution was then mixed with $0.3 \mathrm{~g}$ of mineral for $1 \mathrm{~min}$ and centrifuged for another $15 \mathrm{~min}$ at $3000 \mathrm{~g}$ force. The supernatant was extracted by syringe and filtered with a $0.4 \mu \mathrm{m}$ disc filter. $20 \mu \mathrm{l}$ of $30 \mathrm{wt} \% \mathrm{HCl}$ was added to the filtrate and diluted to $20 \mathrm{ml}$. The final solution was measured by a TOC-L from Shimadzu. The filtration of the cement/water mixture was measured as blank. The PVOH solution with specific concentrations was also measured, for the calculation of PVOH depletion.

\subsection{Zeta potential (electroacoustic) measurement}

Zeta potential was measured using a DT310 from Dispersion Technology. It was calculated according to the colloidal vibration current (CVI), which was induced by ultrasound propagation through a suspension. The principle of this method, as well as its applications, have been described in detail elsewhere [21]. Though this method is able to measure a high solid ratio specimen, high water/ cement ratio suspensions were performed in accordance with an adsorption protocol.

$20 \mathrm{~g}$ of cement powder was mixed with $180 \mathrm{~g}$ of polymer dispersion. The polymer concentration ranges from 0 to $1 \mathrm{wt} \%$, with an increment of $0.25 \mathrm{wt} \%$. Because of high ionic background induced by cement hydration, filtration of the cement suspensions was measured prior to the measurements to determine its ionic vibration current, which was set as background and subtracted from the measured CVI in the presence of cement and latex particles. After that, Zeta potential was calculated with the recorded CVI.

\subsection{Mix design of the samples}

The mix design of the samples is listed in Table 3.

\section{Results and discussion}

\subsection{Surface properties of the latices}

The surface charge density of latex particles is always interesting, especially in regard to their possible interactions with ions present in the cement pore solution and hence in regard to any possible bridging effects by multivalent ion complexation, as well as in regard to electrostatic interactions. Charge titration through a streaming current detector was adopted, to determine any possible interactions with 
Table 3 Mix design of the samples (mg)

\begin{tabular}{lllll}
\hline Mineral $^{\mathrm{a}}$ & Latex $^{\mathrm{b}}$ & PVOH $^{\mathrm{b}}$ & Water $^{\mathrm{c}}$ & Measurements \\
\hline 1000 & $9-450$ & N/A & $8550-8991$ & $\begin{array}{l}\text { Adsorption of latex (Figs. 3, 4,5 and } \\
8\end{array}$ \\
500 & N/A & $2-9$ & $4491-4498$ & $\begin{array}{l}\text { Depletion of PVOH (Figs. 9 and 10) } \\
\text { Depletion of latex in the presence of } \\
\text { PVOH (Fig. 11) }\end{array}$ \\
\hline
\end{tabular}

${ }^{\mathrm{a}}$ Cement, $\mathrm{C}_{3} \mathrm{~S}$ or $\mathrm{C}_{3} \mathrm{~A}$

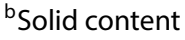

'The amount of polymer dispersions is $9 \mathrm{~g}$; while that of polymer solution is $4.5 \mathrm{~g}$

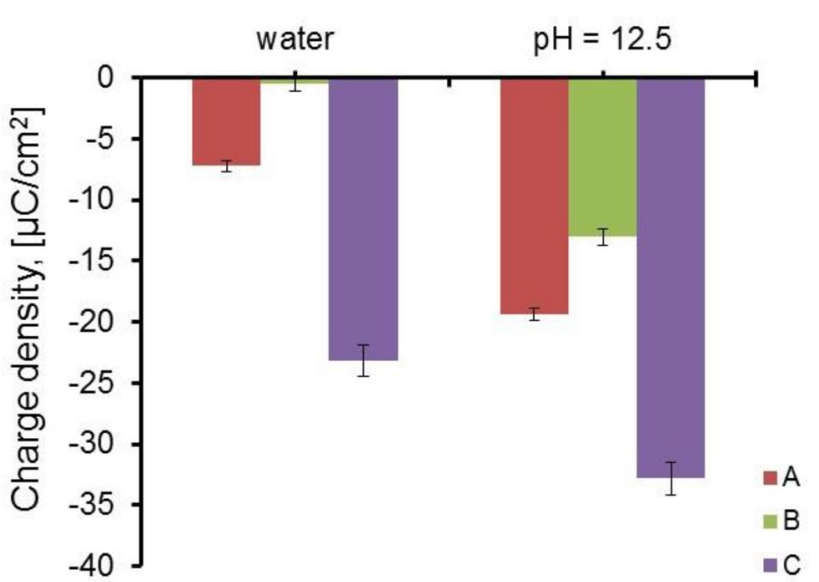

Fig. 2 Particle charge density of latices while dispersed in a neutral or alkaline medium

cations. Figure 2 presents the charge density of the latices in deionized water and alkaline solution. Latex $C$, with an anionic surfactant, possessed the highest charge density, with latex $B$ being almost neutral electrically, but with the nominal non-ionic latex $A$ showing a comparable anionic charge density. The anionic charge density of all the latices increased in an alkaline solution, which might be attributable to the deprotonation of functional groups in the polymer chain or in the grafted as well as adsorbed PVOH. Alternatively, the influence of increased electrical conductivity in the bulk solution cannot be discounted [22]. Latex B was more susceptible to alkaline hydrolysis due to its high content vinylacetate group [23]. As a result, deprotonation of vinylacetate groups from latex $B$ should bring in a higher negative charge density than that of latex $A$. It is not surprising that latex $A$ and $B$ possessed little negative charge in an alkaline solution, but their difference in charge density cannot be explained by their difference in terms of chemical composition.

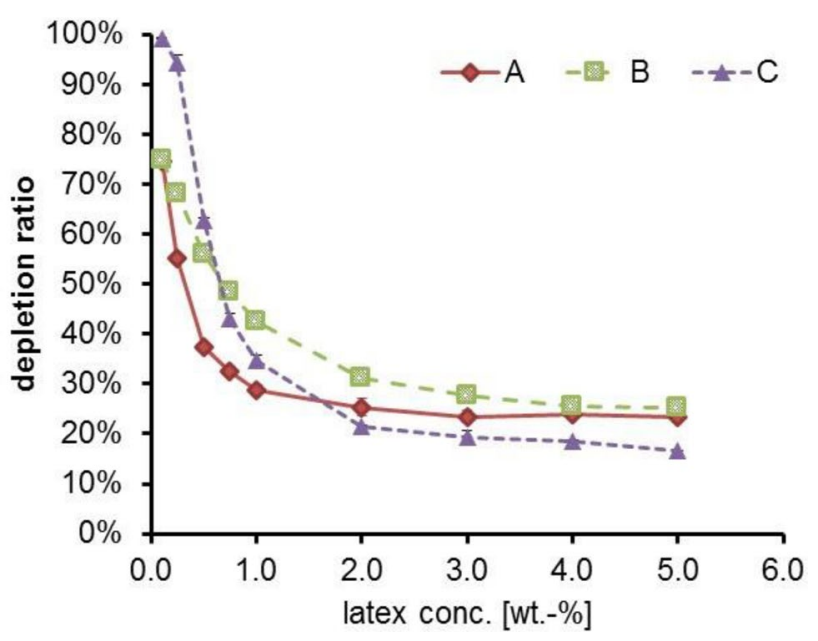

Fig. 3 Depletion ratio of latices in the supernatant as a function of latex concentration

\subsection{Depletion and adsorption of latex on cement minerals}

The depletion ratio, instead of the adsorption amount, was directly measured. There are several possible reasons for the depletion of latex particles, which results in their decreased concentration in the supernatant. Adsorption, sedimentation, foaming or flocculation are the major influence factors. If the colloid is well stabilized, as it was in the case of this study, flocculation should be negligible; with adsorption being desired. However, it was impossible to avoid particles becoming trapped in the sediment. In Fig. 3, an almost constant depletion ratio, at a high concentration, is present for all the latices. It can be inferred that this part of the depletion can be accounted for by the incomplete separation of latex from the sediment, which is only a function of latex concentration. Accordingly, the depleted amount against the latex concentration ( $>0.75 \mathrm{wt} \%$, equal to a polymer cement ratio of 0.068 ) was plotted, as shown in Fig. 4 A good linear relation was found for all the latices. If we assume that this linearly dependent depletion was induced only by sedimentation (insufficient separation) and subtract the value, a new relation 


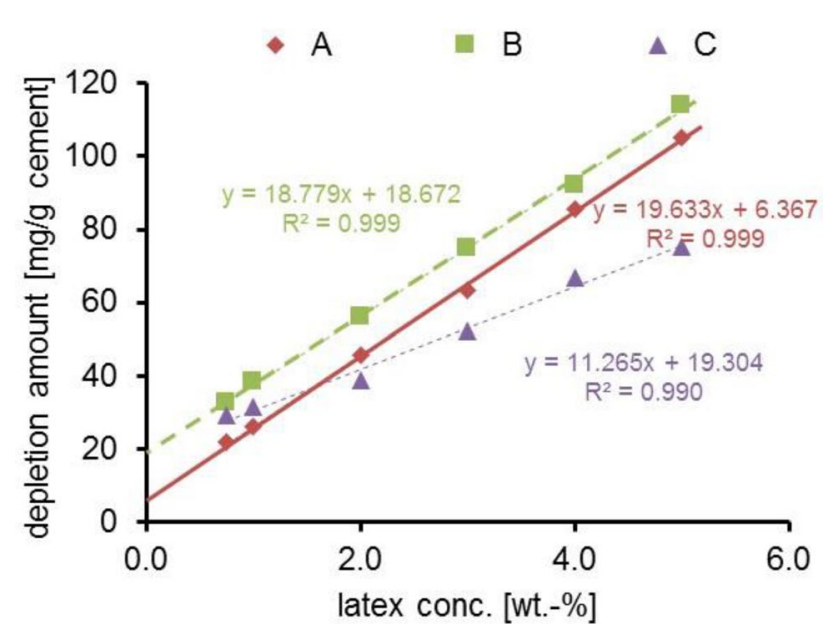

Fig. 4 Linear regression of depletion amount versus latex concentration

between the calculated adsorption amount and the latex concentration is revealed, as presented in Fig. 5. All the latices reached saturated adsorption on the cement surface. At a high latex concentration, the saturation adsorption was thus presented by the intercept of the regression equation. The saturation amounts of $19.3 \mathrm{mg} / \mathrm{g}$ cement for latex $C, 6.4 \mathrm{mg} / \mathrm{g}$ cement for latex $A$ and $18.7 \mathrm{mg} / \mathrm{g}$ for latex $B$ were assumed from the intercept, which fitted well with the curves in Fig. 5. The adsorption of anionic latex reached its saturation point at a polymer cement ratio of around $0.02-0.05$ (equaling a $0.25-0.5 \mathrm{wt} \%$ concentration), which was similar to the findings regarding the anionic latex adsorption on Portland cement [10].

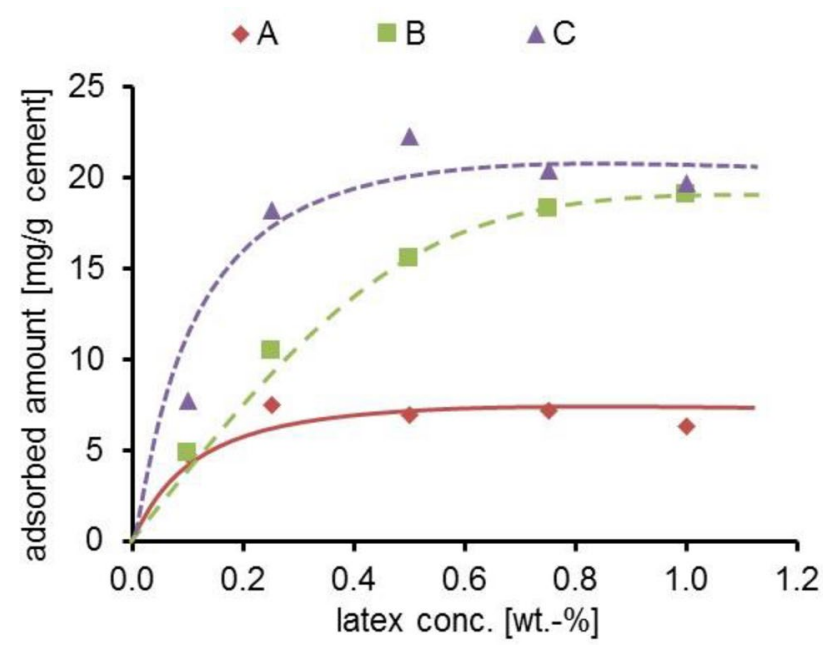

Fig. 5 Calculated adsorption amount of latices by subtracting the unadsorbed amount in sediment
As expected, latex $A$ had little interaction with the cement. Surprisingly, latex $B$ had a remarkably high adsorption amount on the cement and it is difficult to explain this observation considering only the difference between latex $A$ and $B$ in terms of charge density. However, in the Portland cement pore solution, the high ionic strength $[24,25]$ can compress the Debye length of the electrical double layer into the order of $1 \mathrm{~nm}$ [26] while the radius of the $\mathrm{PVOH}$ coil in solution can be at least $5 \mathrm{~nm}$ [27]. When adsorbed onto the surface of VAE latex particles, the adsorption thickness of $\mathrm{PVOH}$ could be more than double its radius in solution [18]. Thus, in the presence of $\mathrm{PVOH}$ corona, both latex $A$ and $B$ can be regarded as non-ionic latex. In order to further investigate the relevance of this interaction with respect to electrokinetic properties, the zeta potential of the cement suspension, against latex concentration, was determined by means of an electroacoustic method. A zeta potential of around $2 \mathrm{mV}$ was found for a pure cement suspension at $\mathrm{pH}=13.3$. As can be seen in Fig. 6 , the inversion of the zeta potential with an increasing dosage of latex $\mathrm{C}$, indicates that the electrokinetic properties of cement particles were altered by adsorbed anionic latex particles. At the same time, a relatively stable value of $-5 \mathrm{mV}$ was found at around 0.50 wt $\%$ latex concentration, which is consistent with the observations regarding the adsorption curve. However, for both latex A and B, no distinguishable change of zeta potential was measured, thereby underlining the non-ionic properties of latices as well as the negligible alteration of electrokinetic properties of cement particles.

The adsorption amount on hydrating clinker phase $\mathrm{C}_{3} \mathrm{~S}$ was also determined, being similar to that of the cement, if the adsorption is expressed as [mg/g mineral]. As an interface phenomena, the application of Specific Surface Area

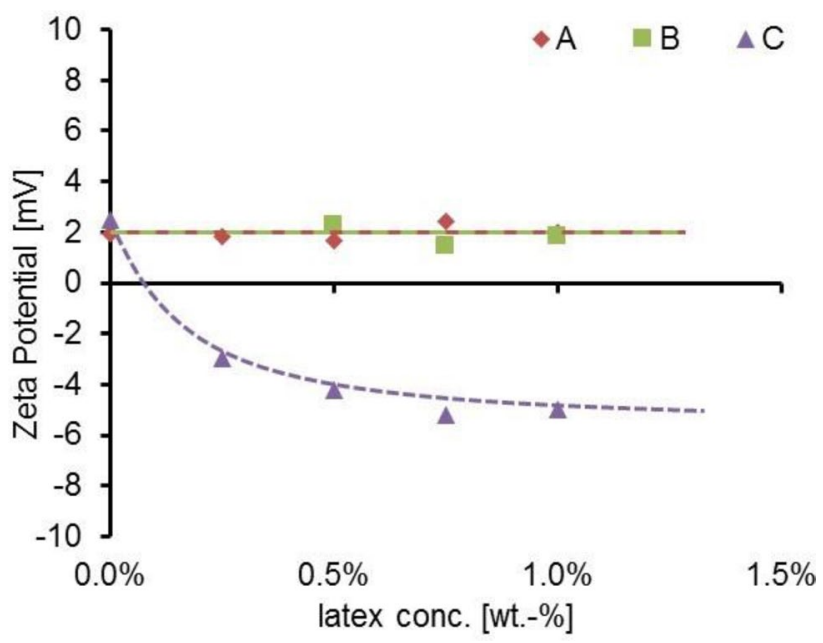

Fig. 6 Zeta potential of cement-latex suspension $(w / c \approx 9)$ as a function of latex concentration 
(SSA) is therefore reasonable. When discussing adsorption, it is difficult to determine an effective surface area, since adsorption sites vary for different adsorbates, as argued by Yamada [28]. Here, three kinds of SSA were determined, as shown in Table 2. For further illustrating the relationship between adsorption and specific surface area, a simple calculation on surface occupation was performed. For ease of calculation, it was assumed that the polydispersity of adsorbed particles is kept unchanged. As such, if the specific surface area of the latex particles is known, surface coverage can be calculated based on hexagonal close-packing, using Eqs. 1 to 2 .

$\varphi=\frac{S_{\text {lat }}}{S_{\text {hex }}}=\frac{\sum_{i=1}^{n} 4 \pi \cdot R_{i}^{2}}{\sum_{i=1}^{n} 2 \sqrt{3} \cdot R_{i}^{2}}=\frac{2 \pi}{\sqrt{3}}$

$\theta=\frac{m \cdot S_{\text {hex }}}{S_{\text {cem }}}=\frac{\sqrt{3} \cdot m \cdot S_{\text {lat }}}{2 \pi \cdot S_{\text {cem }}}$

where $\varphi=$ ratio between specific surface area and equally occupied hexagonal area by projection of the particles; $\mathrm{R}_{\mathrm{i}}=$ radius of individual latex particle; $\mathrm{S}_{\text {lat }}=$ specific surface area of latex particles, $\mathrm{m}^{2} / \mathrm{g} ; \mathrm{S}_{\text {hex }}=$ occupied hexagonal surface area by latex particles; $m=$ adsorbed amount of latex per unit cement amount, $\mathrm{mg} / \mathrm{g} ; \mathrm{S}_{\text {cem }}=$ specific surface area of cement, $\mathrm{m}^{2} / \mathrm{g} ; \theta=$ surface coverage, expressed as $\%$.

The calculated surface coverage, at saturated adsorption on cement, was $\sim 35.4 \%$ for latex $C$, with respect to SSA as determined by laser granulometry, $\sim 19.4 \%$ by Blaine test or $\sim 7.6 \%$ by the BET method, respectively. While the non-equilibrium state was measured in this study, an initial maximal surface coverage between 7.6 and $19.4 \%$ is more consistent with the literature [29], where cationic polystyrene latex was adsorbed on a mica surface, under different ionic strengths. Apparently, BET theory based on gas adsorption includes the internal surface of micropores, while the Blaine test determines the envelope surface of particles [30]. Considering the size of latex particles, the available surface area for latex adsorption should be in-between the surface areas, as measured by the BET and Blaine methods, as illustrated in Fig. 7. Accordingly, the initial maximal surface coverage was calculated as 1.2-3.0\% for latex A and 3.5-8.8\% for latex B. In terms of the Blaine surface, a slightly higher adsorption on $C_{3} S$ than on cement was found for both latex $A$ and $B$ (Fig. 8). A similar result was achieved when the BET surface was applied, implying that adsorption of latex particles is favorable on

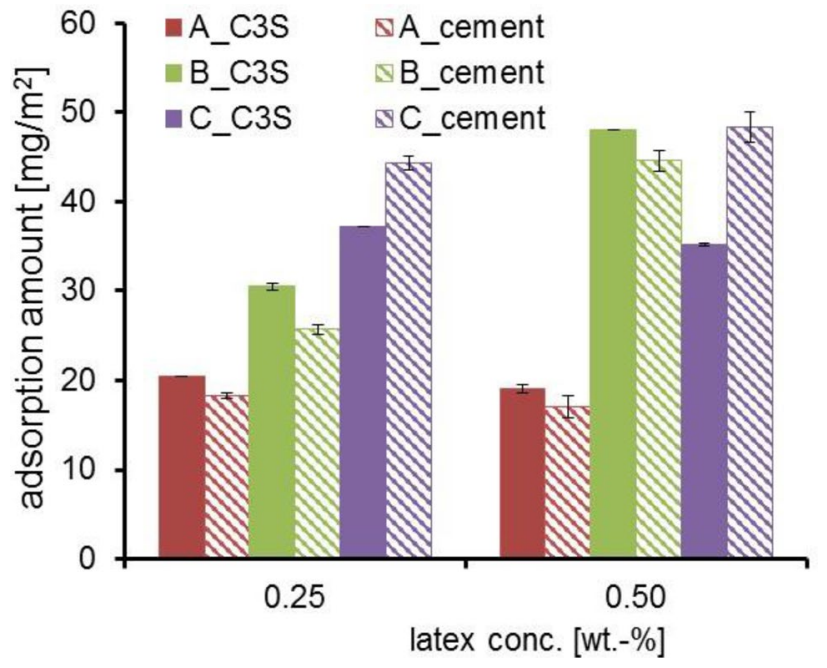

Fig. 8 Calculated adsorption amount on cement and $C_{3} S$ based on specific surface area by Blaine test (solid column: $C_{3} S$; bias column: cement)
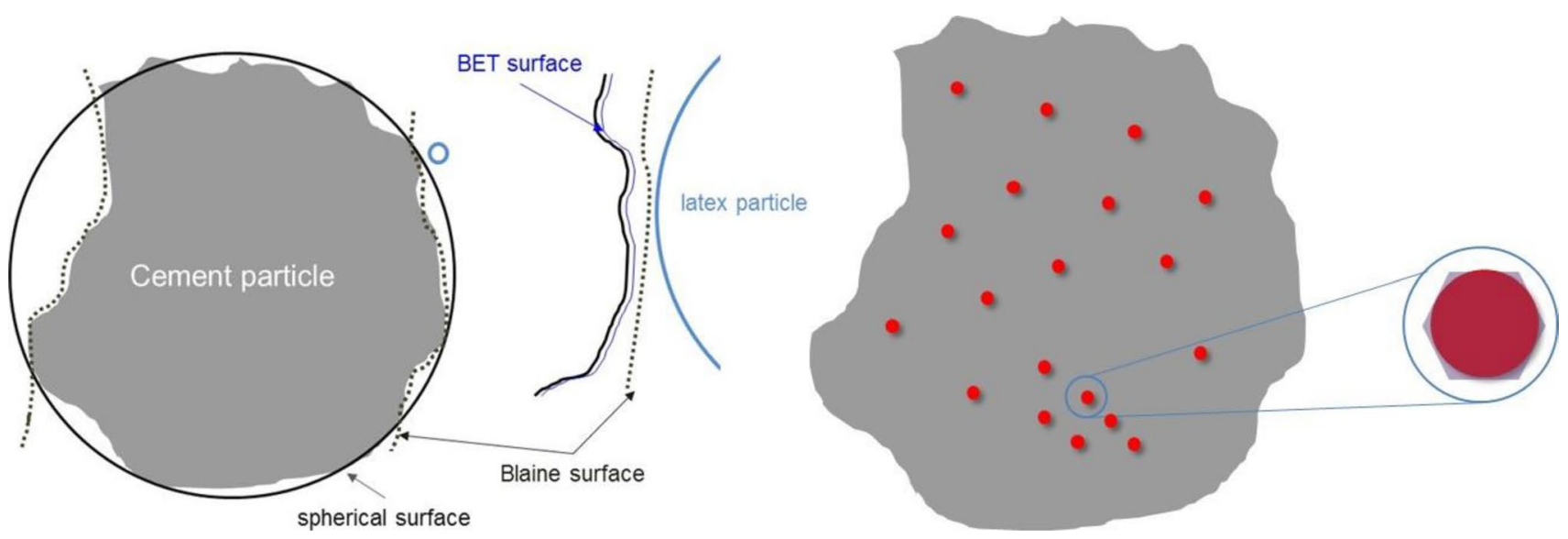

Fig. 7 Left: Schematic illustration of different specific surface areas of cement particles with regard to latex adsorption; right: hexagonal surface area occupied by latex particles 
the surface of $\mathrm{C}_{3} \mathrm{~S}$. Moreover, the low surface coverage was also indirectly proved by monitoring cement hydration in the presence of both latex A and B [31], with the changed kinetics principally related to the serum (without latex particles). If the influence of the serum is eliminated, latex particles alone have negligible effect on cement hydration. Thus, maximal surface coverage of latex $A$ and $B$ on cement surface should be quite low, even if it is estimated on the basis of the concentrated cement-latex suspension.

\subsection{Colloidal interaction between non-ionic VAE latex and Portland cement: the role of PVOH}

As presented in Table 1, approximately $4-5 \% \mathrm{PVOH}$ could be physically separated from latex by ultracentrifugation. The determination of $\mathrm{PVOH}$ adsorption on cement minerals was therefore not only significant in elaborating a possible interaction mechanism, but also in implying possible competitive adsorption. However, the separation of nonadsorbed polymer and mineral particles was not sufficient, due to a limit in centrifugal force in this study. Thus, an equivalence between depletion and adsorption amounts was not established. Instead, adsorption was indicated by the depleted amount, as discussed in Sect. 3.2. Figure 9 presents the depletion amount of $\mathrm{PVOH}$ on the hydrating minerals. Negligible adsorption on $\mathrm{C}_{3} \mathrm{~S}$ was indicated according to the approximate linear depletion. However, $\mathrm{PVOH}$ showed a remarkably high depletion amount on $\mathrm{C}_{3} \mathrm{~A}$, i.e. a much stronger interaction with the aluminate phase. This implies that a higher surface area was available for $\mathrm{PVOH}$ adsorption. Furthermore, when diluting the original 20 wt $\%$ PVOH with a different solution, no significant change in the depletion amount was displayed, implying that the interaction between $\mathrm{PVOH}$ and $\mathrm{C}_{3} \mathrm{~A}$ was neither sensitive to $\mathrm{pH}$ nor sulfate ions (see Fig. 10), irrespective of

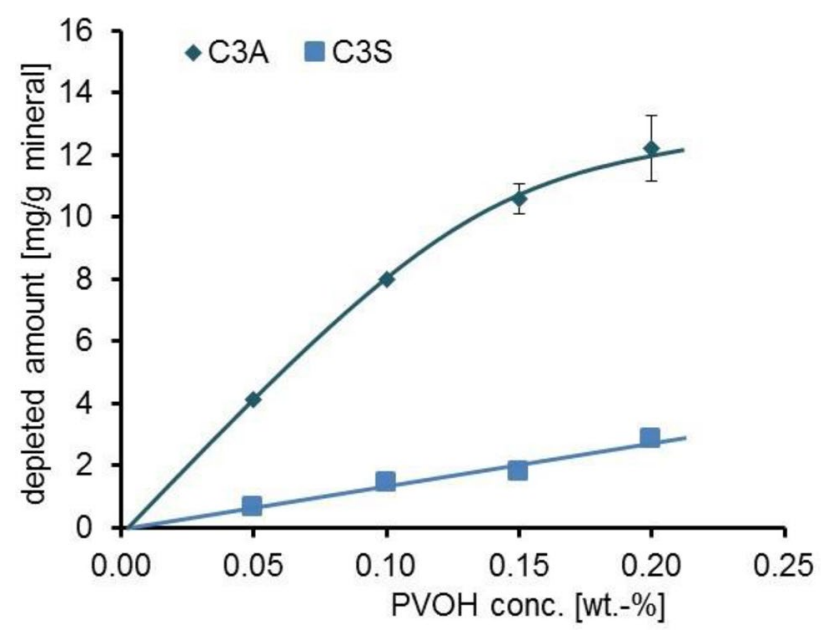

Fig. 9 Depletion amount of PVOH on hydrating minerals

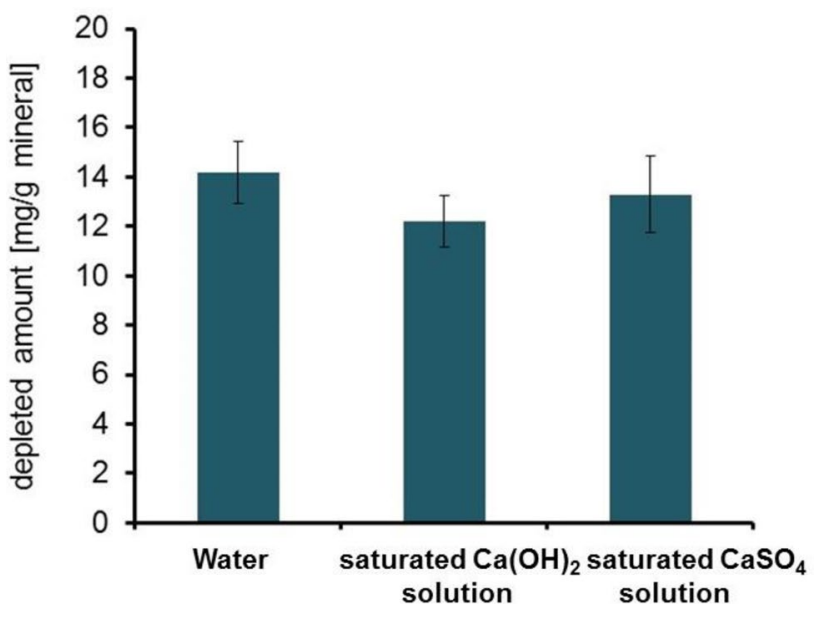

Fig. 10 Depletion amount of PVOH ( $c=0.20 w t \%)$ on hydrating $C_{3} A$ in different ionic environments

the huge surface area either provided by the formation of $\mathrm{C}_{4} \mathrm{AH}_{13}$ in the absence of sulfate, or ettringite in the presence of sulfate.

Firstly, polymer like PVOH provides not only steric stabilization but also depletion stabilization in colloids [32]. Change of polymer concentration in the colloids affects local stabilization of colloidal particles, which may result in deposition of colloidal particles on mineral surfaces (via the Van der Waals force). Secondly, latex particles can adsorb onto the mineral surface via surface PVOH. Thirdly, if PVOH is present on the mineral surface, it can exert steric repulsion between the mineral surface and the latex particle. This may be speculated from Fig. 8, where latex adsorption was higher on the surface of $\mathrm{C}_{3} S$ than on cement. Since PVOH showed strong interaction with $C_{3} A$, accumulation of $\mathrm{PVOH}$ on the surface of the aluminate phase can be expected. As a result, the silicate surface was more favorable for the adsorption of the latex particles.

Nearly half of the $\mathrm{PVOH}$ added during polymerization was freely dispersed in the final Vinyl-acetate latex [18]. The 'two components' concept resulted in a unique interaction of the VAE latex with the mineral surface. By adding PVOH to the polymer dispersions (Fig. 11), the depletion ratio of latex $B$ was less affected, while that of latex A decreased subsequently, i.e. the reduction in depletion ratio was more pronounced for latex $A$. This inconsistent change in depletion ratio between the two latices indicates that the state of PVOH referring the polymer adsorbed on the solid surface or dispersed in the solution, has an important role on adsorption behavior for polymer stabilized latex (protective colloid). In other words, dynamic change in steric repulsion between polymer chains and osmotic pressure in the solution, may dominate the adsorption behavior observed in this study. 


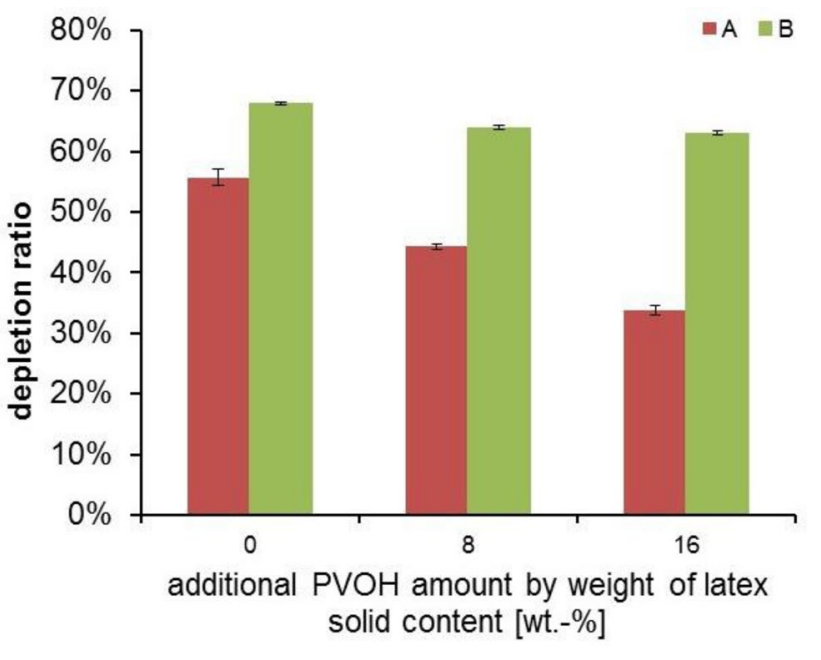

Fig. 11 Depletion ratio of latex A and B at 0.25 wt $\%$ concentration with additional $\mathrm{PVOH}$

\section{Conclusion}

Colloidal interaction between VAE latex stabilized by $\mathrm{PVOH}$ and Portland cement was found to be less relevant to the surface charge of latex, than to the role of $\mathrm{PVOH}$, which is different from electrostatic/electrosteric stabilized latex. Initial surface coverage on cement minerals is subject to both the adsorption amount and the particle size of the colloids (or specific surface area). Considering this, a weak influence of the VAE latex, stabilized by $\mathrm{PVOH}$ on the initial dissolution of cement minerals, can be expected. As such, cement hydration should be less affected by the latex particles. However, a strong interaction of $\mathrm{PVOH}$ with the aluminate phase was observed, which undoubtedly affects the hydration kinetics of cement at an early age. The interaction of PVOH with cement minerals would reversely affect the adsorption of the latex particles, which would make the interaction between the VAE latex stabilized by $\mathrm{PVOH}$ and cement much more complex.

Acknowledgements Yu Jin gratefully acknowledges the scholarship provided by DAAD (German academic exchange service). The authors also greatly appreciate Dr. Ulf Dietrich for the synthesis of model latices and Dr. Wolf-Dieter Hergeth for the helpful discussions. We also appreciate Ms. Jessica Grewe for the TOC measurements.

\section{Compliance with ethical standards}

Clarification This work is part of Yu Jin's PhD thesis, which can be found in the repository from TU Berlin (https://depositonce.tu-berli n.de/).

Conflict of interest The authors declare that they have no conflict of interest.

\section{References}

1. Ohama Y (1995) Handbook of polymer-modified concrete and mortars. Properties and process technology. Noyes Publications, Park Ridge

2. Chandra S, Ohama Y (1994) Polymers in concrete. CRC Press, Boca Raton

3. Ohama Y (1998) Polymer-based admixtures. Cem Concr Compos 20(2-3):189-212. https://doi.org/10.1016/S0958-9465(97)00065 $-6$

4. van Gemert D (2007) Cement-concrete and concrete-polymer composites. Two merging worlds. In: Kyu-Seok Y (ed) Polymers in concrete, vol 1. Kangwon National University, Chuncheon, pp 3-15

5. Sakai E, Sugita J (1995) Composite mechanism of polymer modified cement. Cem Concr Res 25(1):127-135. https://doi. org/10.1016/0008-8846(94)00120-N

6. Su Z, Sujata K, Bijen JMJM et al (1996) The evolution of the microstructure in styrene acrylate polymer-modified cement pastes at the early stage of cement hydration. Adv Cem Based Mater 3(3-4):87-93. https://doi.org/10.1016/S1065-7355(96)90041-3

7. Jenni A, Holzer L, Zurbriggen R et al (2005) Influence of polymers on microstructure and adhesive strength of cementitious tile adhesive mortars. Cem Concr Res 35(1):35-50. https://doi. org/10.1016/j.cemconres.2004.06.039

8. Rottstegge J, Arnold M, Herschke L et al (2005) Solid state NMR and LVSEM studies on the hardening of latex modified tile mortar systems. Cem Concr Res 35(12):2233-2243. https://doi. org/10.1016/j.cemconres.2004.10.003

9. Merlin F, Guitouni $\mathrm{H}$, Mouhoubi $\mathrm{H}$ et al (2005) Adsorption and heterocoagulation of nonionic surfactants and latex particles on cement hydrates. J Colloid Interface Sci 281(1):1-10. https:// doi.org/10.1016/j.jcis.2004.08.042

10. Plank J, Gretz M (2008) Study on the interaction between anionic and cationic latex particles and Portland cement. Colloids Surf A 330(2-3):227-233. https://doi.org/10.1016/j.colsu rfa.2008.08.005

11. Kaufmann J, Winnefeld F, Zurbriggen R (2012) Polymer dispersions and their interaction with mortar constituents and ceramic tile surfaces studied by zeta-potential measurements and atomic force microscopy. Cem Concr Compos 34(5):604-611. https://doi.org/10.1016/j.cemconcomp.2012.01.012

12. Lu Z, Kong X, Zhang C et al (2017) Effect of colloidal polymers with different surface properties on the rheological property of fresh cement pastes. Colloids Surf A 520:154-165. https://doi. org/10.1016/j.colsurfa.2017.01.067

13. Santhiya D, Subramanian S, Natarajan KA et al (1999) Surface chemical studies on the competitive adsorption of poly(acrylic acid) and poly(vinyl alcohol) onto alumina. J Colloid Interface Sci 216(1):143-153

14. Labidi NS, Djebaili A (2008) Studies of the mechanism of polyvinyl alcohol adsorption on the calcite/water interface in the presence of sodium oleate. J Miner Mater Charact Eng 7(2):147-161

15. Silva DA, Monteiro PJM (2005) Analysis of $C_{3} A$ hydration using soft X-rays transmission microscopy: effect of EVA copolymer. Cem Concr Res 35(10):2026-2032. https://doi.org/10.1016/j. cemconres.2005.02.002

16. Silva DA, Monteiro PJM (2005) Hydration evolution of $C_{3} S-E V A$ composites analyzed by soft X-ray microscopy. Cem Concr Res 35(2):351-357. https://doi.org/10.1016/j.cemconres.2004.05.049

17. Betioli AM, Gleize PJP, John VM et al (2012) Effect of EVA on the fresh properties of cement paste. Cem Concr Compos 34(2):255260. https://doi.org/10.1016/j.cemconcomp.2011.10.004

18. Carrà S, Sliepcevich A, Canevarolo A et al (2005) Grafting and adsorption of poly(vinyl) alcohol in vinyl acetate 
emulsion polymerization. Polymer 46(4):1379-1384. https:// doi.org/10.1016/j.polymer.2004.11.061

19. Gilmore CM, Poehlein GW, Schork FJ (1993) Modeling poly(vinyl alcohol)-stabilized vinyl acetate emulsion polymerization. I. Theory. J Appl Polym Sci 48(8):1449-1460

20. Jin Y (2016) Interaction between vinyl acetate-ethylene latex stabilized with polyvinyl alcohol and Portland cement. Ph. D. dissertation, Technische Univeristät Berlin

21. Dukhin AS, Goetz PJ (2002) Ultrasound for characterizing colloids. Particle sizing, zeta potential, rheology, vol 15. Elsevier, Amstedam

22. Chen J, Heitmann JA, Hubbe MA (2003) Dependency of polyelectrolyte complex stoichiometry on the order of addition. 1. Effect of salt concentration during streaming current titrations with strong poly-acid and poly-base. Colloids Surf A Physicochem Eng Asp 223(1-3):215-230. https://doi.org/10.1016/s0927 -7757(03)00222-x

23. Davies RFB, Reynolds GEJ (1968) Alkaline hydrolysis of aqueous polymer dispersions, particularly vinyl acetate copolymers. J Appl Polym Sci 12(1):47-58. https://doi.org/10.1002/ app.1968.070120106

24. Rothstein D, Thomas JJ, Christensen BJ et al (2002) Solubility behavior of $\mathrm{Ca}-, \mathrm{S}-, \mathrm{Al}-$, and Si-bearing solid phases in Portland cement pore solutions as a function of hydration time. Cem Concr Res 32(10):1663-1671. https://doi.org/10.1016/S0008 $-8846(02) 00855-4$

25. Al Kelzenberg, Tracy SL, Christiansen BJ et al (1998) Chemistry of the aqueous phase of ordinary Portland. J Am Ceram Soc 81(9):2349-2359
26. Flatt RJ, Bowen P (2003) Electrostatic repulsion between particles in cement suspensions: domain of validity of linearized Poisson-Boltzmann equation for nonideal electrolytes. Cem Concr Res 33(6):781-791. https://doi.org/10.1016/S0008 -8846(02)01059-1

27. Koopal LK, Lyklema J (1979) Characterization of adsorbed polymers from double layer experiments. J Electroanal Chem Interfacial Electrochem 100(1-2):895-912. https://doi.org/10.1016/ S0022-0728(79)80208-9

28. Yamada K (2011) Basics of analytical methods used for the investigation of interaction mechanism between cements and superplasticizers. Cem Concr Res 41(7):793-798. https://doi. org/10.1016/j.cemconres.2011.03.007

29. Johnson CA, Lenhoff AM (1996) Adsorption of charged latex particles on mica studied by atomic force microscopy. J Colloid Interface Sci 179(2):587-599

30. Allen T (1997) Particle size measurement. Powder technology series, 5th edn. Chapman \& Hall, London

31. Jin Y, Stephan D (2018) Hydration kinetics of Portland cement in the presence of vinyl acetate ethylene latex stabilized with polyvinyl alcohol. J Mater Sci 53(10):7417-7430. https://doi. org/10.1007/s10853-018-2074-1

32. Hiemenz PC, Rajagopalan R (1997) Principles of colloid and surface chemistry, 3rd edn. Marcel Dekker, New York 